\title{
DATA MINING DENGAN METODE KLASIFIKASI NAÏVE BAYES UNTUK MENGKLASIFIKASIKAN PELANGGAN
}

\author{
Eka Miranda, Julisar \\ Program Sistem Informasi, Program Studi Sistem Informasi, Universitas Bina Nusantara \\ JIn. K.H. Syahdan No. 9, Palmerah, Jakarta Barat, 11480 \\ Telp. (021) 5345830 \\ E-mail: ekamiranda@binus.ac.id, julisar@binus.ac.id
}

\begin{abstract}
ABSTRAKSI
Tujaun penelitian ini adalah mengklasifikasikan pelanggan berdasarkan tabel transaksi dengan pendekatan knowledge discovery from data (KDD) dan metode data mining naïve bayes classifier dengan manfaat menghasilkan pengetahuan yang berguna untuk mengambil keputusan yang terkait dengan mengelola pelanggan. Untuk menggali pengetahuan dari data yang berjumlah besar tersebut, menggunakan data mining dan metode Naïve Bayes Classifier. Untuk mengklasifikasikan pelanggan digunakan tabel transaksi dari proses pembelian kendaraan bermotor dengan pendekatan Knowledge Discovery from Data (KDD) dan metode data mining Naïve Bayes Classifier. Metode yang digunakan pada penelitian terdiri atas metode pengumpulan data yang digunakan untuk pencariaan kebutuhan informasi dengan menggunakan fact finding technique menurut Thomas Connolly dan Carolyn Begg, yang meliputi: Wawancara (Interview), Persyaratan (Requerements) atau Preferensi (Preferences) dan proses penemuan pengetahuan menggunakan pendekatan Knowledge Discovery from Data (KDD). Penellitian ini mengklasifikasikan pelanggan menjadi dua kelas yaitu kelas pelanggan potensial dan pelanggan tidak potensial dengan menggunakan atribut prediksi klasifikasi terdiri atas Pekerjaan, Jenis Bayar, Tenor dan Usia. Hasil dari penelitian menunjukan bahwa Naïve Bayes Classifier telah dapat mengklasifikasikan pelanggan menjadi dua kelas yaitu kelas pelanggan potensial dan pelanggan tidak potensial dengan nilai akurasi masing-masing sebagai berikut : Sensitivity $97 \%$, Specificity 99,8\%, Precision 99,8\%, Recall 97\%, Accuracy 97\%, Error Rate 3\%.
\end{abstract}

Kata Kunci: Naïve Bayes Classifier, Knowledge Discovery from Data (KDD), Klasifikasi Pelanggah 


\section{PENDAHULUAN}

Di dalam era digital saat ini, kemudahan penyimpanan data dan akses data menjadi sesuatu yang sangat penting. Data yang diterima oleh perusahaan, diolah menjadi informasi sehingga menjadi pengetahuan yang dapat digunakan untuk perencanaan, pengambilan keputusan, monitoring, evaluasi. Untuk menggali pengetahuan dari data yang sudah diolah, dibutuhkan metode tertentu sehingga pengetahuan tersebut bisa bermanfaat bagi pemakai, Metode yang digunakan adalah data mining. Data mining digunakan untuk mengekstraksi pengetahuan secara otomatis dari data berukuran besar dengan mencari pola-pola menarik yang terkandung dalam data tersebut.

Metode data mining yang digunakan untuk melakukan klasifikasi data adalah nä̈ve bayes classifier, decision tree, dan rule based. Untuk penelitian ini akan digunakan metode Nä̈ve Bayes Classifier. Keunggulan menggunakan metode nä̈ve bayes classifier dibandingkan metode lainnya adalah merupakan metode pengklasifikasian statistik yang dapat digunakan untuk memprediksi probabilitas keanggotaan dari suatu kelas, selain itu terbukti memiliki akurasi dan kecepatan yang tinggi saat diaplikasikan ke dalam database yang besar (Jiawei, 2012).

Menurut Jiawei Han, Micheline Kamber, dan Jian Pei (2012:8) Data Mining adalah proses menemukan pola yang menarik dan pengetahuan dari sejumlah besar data, sumber data dapat mencakup database, datawarehouse, web, repositori informasi lainnya, atau data yang dialirkan ke dalam sistem dinamis.

Menurut Jiawei Han, Micheline Kamber, dan Jian Pei (2012:350) Nä̈ve Bayes Classifier adalah pengklasifikasi statistik, mereka bisa memprediksi probabilitas keanggotaan kelas seperti probabilitas bahwa tuple diberikan untuk kelas tertentu.

Di dalam proses penemuan pengetahuan dengan menggunakan data mining digunakan pendekatan Knowledge Discovery from Data (KDD). Menurut Jiawei Han, Micheline Kamber, dan Jian Pei (2012:7), Knowledge Discovery from Data (KDD) adalah otomatisasi atau ekstraksi dari pola yang mempresentasikan suatu pengetahuan yang secara implisit disimpan atau dicatat pada database yang besar, data warehouse, web, penyimpanan informasi dalam jumlah besar lainnya, atau aliran data dan sebuah tahapan dalam data mining untuk mendapatkan pengetahuan.

Menurut Jiawei Han, Micheline Kamber, dan Jian Pei (2012:327), Classification adalah suatu bentuk analisis data, bahwa ekstrak model menggambarkan kelas data penting, model seperti ini disebut pengklasifikasi, memprediksi kategori kelas dari suatu objek yang labelnya tidak di ketahui.

Fathur Rahman dan Muhammad Iqbal Firdaus (2016) telah melakukan penelitian penggunaan nä̈ve bayes classifier untuk prediksi hasil belajar siswa Sekolah Menengah Pertama (SMP). Hasilnya bahwa pengujian klasifikasi dari hasil belajar siswa pada penelitian ini disimpulkan bahwa algoritma naïve bayes memiliki kinerja yang baik dari segi akurasi, presisi dan recall walaupun dari jumlah akurasi yang hanya 56,79\% masih tergolong hasil yang rendah dibandingkan beberapa model data mining yang lainnya. Hal ini karena banyaknya input tidak terlalu relevan dan algoritma yang diujikan tidak terlalu sensitif dengan input yang tidak terlalu relevan tersebut.

Mujib Ridwan, Hadi Suyono, dan M. Sarosa (2013) penelitian ini difokuskan untuk mengevaluasi kinerja akademik mahasiswa pada tahun ke-2 dan diklasifikasikan dalam kategori mahasiswa yang dapat lulus tepat waktu atau tidak. Data input akan diproses menggunakan teknik data mining algoritma naïve bayes classifier (NBC) untuk membentuk tabel probabilitas sebagai dasar proses klasifikasi kelulusan mahasiswa. Hasilnya adalah pengujian pada data mahasiswa angkatan 2005-2009 data mining nä̈ve bayes classifier menghasilkan nilai precision, recall, dan accuracy masing-masing $83 \%, 50 \%$, dan $70 \%$.

Yisti Vita Via, Budi Nugroho, dan Alfian Syafrizal (2015) penelitian ini menganalisis tentang pengelompokan data kanker payudara untuk mengetahui kanker tersebut termasuk kanker jinak atau kanker ganas. Untuk mengklasifikasi tingkat keganasan dapat dilakukan dengan pemanfaatan bioinformatic dengan menggunakan teknik data mining salah satuya adalah algoritma nä̈ve bayes classifier (NBC). Dari hasil pengujian dengan confusion matrix diketahui bahwa NBC yang diterapkan untuk melakukan klasifikasi tingkat keganasan kanker payudara memiliki akurasi pola yang cukup besar yaitu $97,82 \%$, sedangkan error rate yang dihasilkan sebesar $2,18 \%$.

Pada penelitian ini data mining digunakan untuk mengklasifikasikan pelanggan berdasarkan tabel transaksi dengan pendekatan knowledge discovery from data (KDD) dan metode data mining nä̈ve bayes classifier. Pelanggan dapat dikelompokan salah satunya berdasarkan demografi. Demografi pada dasarnya adalah klasifikasi atau pengelompokkan yang didasarkan pada peta kependudukan. Karakteristik demografi merujuk ke statistik populasi yang amat penting dan dapat diukur. Karakteristik demografi dapat meliputi usia, gender, daya beli dan pendidikan.

Abdul Basith (2014) telah melakukan penelitian untuk menganalisis dan menjelaskan pengaruh kualitas produk dan kualitas pelayanan terhadap kepuasan pelanggan dan loyalitas pelanggan. 
Hasil penelitian menunjukkan bahwa terdapat pengaruh yang signifikan antara kualitas produk terhadap kepuasan pelanggan, kualitas pelayanan terhadap kepuasan pelanggan dan kepuasan pelanggan terhadap loyalitas pelanggan.

Dewa Ayu (2017) menjelaskan pengaruh customer relationship management dan kepuasan pelanggan terhadap loyalitas pelanggan. Hasil penelitian ini menunjukkan bahwa customer relationship management dan kepuasan pelanggan memiliki pengaruh signifikan secara parsial terhadap loyalitas pelanggan dimana kepuasan pelanggan.

Dari penelitian yang dilakukan oleh Abdul Basith (2014) dan Dewa Ayu (2017) dapat dilihat bahwa menjaga pelanggan agar setia membeli produk yang dijual oleh perusahaan adalah hal yamg krusial.

Tujaun penelitian ini adalah mengklasifikasikan pelanggan berdasarkan tabel transaksi dengan pendekatan knowledge discovery from data (KDD) dan metode data mining nä̈ve bayes classifier dengan manfaat penelitian untuk menghasilkan pengetahuan yang berguna dalam membantu mengambil keputusan yang terkait dengan mengelola pelanggan.

\section{METODE PENELITIAN}

\section{Metode Pengumpulan Data}

Metode yang digunakan untuk pengumpulan data dalam pencariaan kebutuhan informasi menggunakan Fact Finding Technique menurut Thomas Connolly dan Carolyn Begg (2015:375) adalah:

a. Wawancara (Interview)

Wawancara dilakukan kepada responden dengan tingkat minimal manager terkait informasi yang dibutuhkan dalam mendukung proses penelitian yang akan dilakukan. Dari hasil wawancara diperoleh informasi kelas pelanggan yang akan dibuat dan atribut prediksi untuk klasifikasi.

b. Persyaratan (Requerements) atau Preferensi (Preferences)

Melakukan observasi untuk mengetahui persyaratan yang ada untuk digunakan pada proyek penelitian ini. Dari hasil tahap ini diperoleh persyaratan untuk tiap kelas pelanggan.

\section{Knowledge Discovery from Data (KDD)}

Proses Knowledge Discovery from Data (KDD) ini menggunakan langkah-langkah menurut Jiawei Han, Micheline Kamber, dan Jian Pei (2012:6,7,8), yang meliputi :

a. Data Cleansing

Untuk menghilangkan kebisingan dan data yang tidak konsisten.

b. Data Integration
Yaitu beberapa sumber data dapat digabungkan dengan melakukan pembersihan data, dan integrasi data sebagai langkah pre-processing.

c. Data Selection

Memilih data yang relevan dengan tugas analisis yang diambil dari database.

d. Data Transformation

Data diubah dan dikonsolidasikan ke dalam bentuk yang sesuai untuk diproses dengan teknik data mining dengan melakukan ringkasan atau agregasi operasi.

e. Data Mining

Proses penting yaitu metode cerdas yang diterapkan untuk mengekstrak pola data.

f. Pattern Evaluation

Untuk mengidentifikasi pola-pola yang benarbenar menarik yang mewakili pengetahuan.

g. Knowledge Presentation

Yaitu visualisasi dan pengetahuan dengan teknik representasi yang digunakan untuk menyajikan pengetahuan pengguna.

\section{HASIL DAN DISKUSI}

\section{Urgensi Penelitian}

Urgensi yang melatar-belakangi penelitian ini adalah:

a. Kebutuhan untuk dapat menganalisis dan mengelompokkan pelanggan ke dalam kelas yang sudah ditentukan dengan manfaat untuk menghasilkan pengetahuan yang berguna dalam membantu mengambil keputusan yang terkait dengan mengelola pelanggan.

b. Kebutuhan untuk mengetahui hubungan antara atribut yang telah dipilih dengan kelas yang telah terbentuk.

c. Kebutuhan untuk mengetahui profil tiap kelas pelanggan.

\section{Dataset}

Data yang dihasilkan dari proses pembelian kendaraan bermotor sebagai dataset dalam penelitian ini.

Tabel yang digunakan untuk mengklasifikasikan pelanggan adalah tabel transaksi yang dihasilkan dari proses pembelian kendaraan bermotor. Atribut tabel terdiri atas KODE_DEALER, NAMA_DEALER, NO_MESIN, NAMA_STNK, ALAMAT, KELURAHAN, KECAMATAN, KOTA, NO_HP, NO_TELP, TGL_PEMBELIAN, NIK_SALESFORCE, SEX, KD_JOB, AGAMA, JNS_BAYAR, TENOR, TGL_LAHIR, DIGUNAKAN, KD_PEMAKAI, MTRSBL, JNS SKR, HOBI, STATUS VALIDASI, REMINDER_KPB1, DEALER_KPB1, REMINDER_KPB2,

ALASAN_KPB2,

TGL_SERVICE_KPB3, ALASAN_KPB3,
TGL_SERVICE_KPB1, ALASAN_KPB1, DEALER_KPB2, REMINDER_KPB3, DEALER_KPB3, REMINDER_KPB4, 


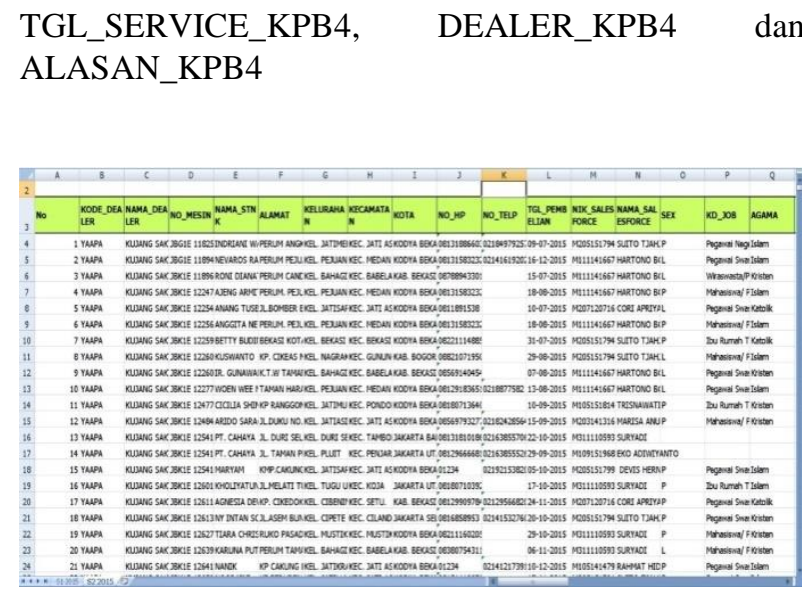

Gambar 1. Sumber Data 1



Gambar 2. Sumber Data 2

Gambar 1 dan 2 merupakan dataset yang digunakan pada penelitian ini. Data ini diperoleh dari hasil proses pembelian kendaraan bermotor yang disimpan di dalam database. Data yang ada pada Gambar 1 dan 2 merupakan data yang belum melalui proses cleaning dan berjumlah 4348 record. Tahap selnjutnya akan dilakukan data cleaning. Data cleaning adalah proses pengahapusan data yang tidak dipakai dan data yang tidak konsisten. Holdout method kemudian digunakan untuk menentukan jumlah data yang digunakan untuk data training $(75 \%$ dari jumlah dataset) dan data testing (25\% dari jumlah dataset). Dengan pendekatan holdout method diperoleh 3261 record digunakan sebagai data training dan 1087 record digunakan sebagai data testing.

\section{Attribute Selection}

Pada tahap ini dilakukan pemilihan atribut yang akan digunakan untuk mengklasifikasikan pelanggan. Atribut ini selanjutnya disebut dengan predictor attribute, yang terdiri atas : Kd_Job, Jenis_Bayar. Tenor dan Tgl_Lahir. Data hasil tahap attribute selection dapat dilihat pada Gambar 3.

\begin{tabular}{|c|c|c|c|}
\hline KD_JOB & JNS_BAYAR & TENOR & TGL_LAHIR \\
\hline Guru/Dosen & Cash & 0 & 24-SEP-71 \\
\hline Ibu Rumah Tangga & Cash & 0 & 15-DEC-96 \\
\hline Pegawai Swasta & Credit & 35 & 24-ОСТ-13 \\
\hline Pegawai Swasta & Credit & 35 & 24-ОСТ-13 \\
\hline Ibu Rumah Tangga & Cash & 0 & $24-0 С Т-13$ \\
\hline Pegawai Swasta & Cash & 0 & 04-DEC-70 \\
\hline Pegawai Swasta & Cash & 0 & 24-ОСТ-13 \\
\hline Guru/Dosen & Cash & 0 & 24-ОСТ-13 \\
\hline Ibu Rumah Tangga & Credit & 11 & 08-FEB-70 \\
\hline Pegawai Swasta & Credit & 34 & 30-APR-88 \\
\hline Mahasiswa/ Pelajar & Cash & 0 & 26 -FEB-16 \\
\hline Pegawai Swasta & Cash & 0 & 22-AUG-80 \\
\hline Pegawai Swasta & Cash & 0 & 08-JUN-74 \\
\hline Pegawai Swasta & Cash & 0 & $22-N O V-77$ \\
\hline Pegawai Swasta & Cash & 0 & 05-APR-67 \\
\hline Pegawai Swasta & Cash & 0 & $25-0$ - T- 63 \\
\hline Ibu Rumah Tangga & Cash & 0 & 28-FEB-98 \\
\hline Pegawai Swasta & Cash & 0 & 25-DEC-76 \\
\hline Pegawai Swasta & Cash & 0 & 15-APR-79 \\
\hline Pegawai Swasta & Cash & 0 & $20-D E C-51$ \\
\hline Pegawai Swasta & Cash & 0 & 04-APR-77 \\
\hline Pegawai Swasta & Cash & 0 & 23-FEB-68 \\
\hline Guru/Dosen & Credit & 34 & 07-MAR-68 \\
\hline Pegawai Swasta & Cash & 0 & 01-JUN-92 \\
\hline Guru/Dosen & Credit & 34 & 31-MAR-88 \\
\hline Ibu Rumah Tangga & Credit & 35 & 28-JUN-64 \\
\hline Pegawai Swasta & Cash & 0 & 25-DEC-64 \\
\hline Pegawai Swasta & Cash & 0 & 08 -FEB-68 \\
\hline Mahasiswa/ Pelajar & Credit & 35 & 20-DEC-70 \\
\hline 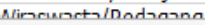 & rach & $n$ & $10 M \triangle D 72$ \\
\hline
\end{tabular}

Gambar 3. Data hasil tahap attribute selection

\section{Generalization}

Data generalization bertujuan untuk mengubah low level data menjadi high level data. Adapun dalam hal ini data diubah dalam bentuk categorical dari masingmasing atribut. Berikut ini adalah bentuk high level data dalam caterogical pada masing-masing atribut:

1. Usia

- $21-50$

- $<=20$ atau $>=51$

2. Jenis Pembayaran

- Cash

- Credit

3. Tenor

- $\quad<=25$ bulan

- $>=26$ bulan

4. Pekerja

- Yes

- No

\section{Identifikasi Kelas yang Digunakan}

Pada penelitian ini pelanggan dikelompokan ke dalam dua kelas: Pelangan berpotensial dan tidak berpotensial menjadi pembeli kembali. Adapun definsi dari tiap kelas dapat dilihat pada Tabel 1.

Tabel 1. Definisi tiap kelas

\begin{tabular}{|c|c|c|c|c|}
\cline { 2 - 5 } \multicolumn{1}{c|}{} & Pekerjaan & Jenis Bayar & Tenor & Usia \\
\hline Potensial & $\begin{array}{c}\text { Pekerja }= \\
\text { "yes" }\end{array}$ & $\begin{array}{c}\text { Cash } \text { atau } \\
\text { Credit }\end{array}$ & $<=25$ & $21-50$ \\
\hline $\begin{array}{c}\text { Tidak } \\
\text { Potensial }\end{array}$ & $\begin{array}{c}\text { Pekerja }= \\
\text { "no" }\end{array}$ & Credit & $>=25$ & $\begin{array}{c}<=20 \text { atau } \\
>=50\end{array}$ \\
\hline
\end{tabular}


Untuk melakukan klasifikasi Nä̈ve Bayes Classification digunakan data testing. Berikut adalah contoh perhitungan kelas Pelanggan Potensial :

- PCi: $\mathrm{P}($ Potensial $)=(\mathrm{Jml}$ Potensial $/ \mathrm{Jml}$ Data $)=$ Total $\mathrm{P}($ Tidak Potensial $)=(\mathrm{Jml}$ Tidak Potensial $/$ $\mathrm{Jml}$ Data $)=$ Total $\mathrm{P}($ Potensial $)=1902 / 3261=0.58$ $\mathrm{P}($ Tidak Potensial $)=1359 / 3261=0.41$

- $\quad$ Compute $P(X \mid C i)$ for each class

$\mathrm{P}($ Pekerja $=$ "No" $\mid$ Potensial $=$ "Yes" $)=931 / 1902$ $=0.48$

$\mathrm{P}($ Pekerja $=$ "No" $\mid$ Potensial $=$ "No" $)=639 / 1359=$ 0.47

$\mathrm{P}($ Jns_Bayar $=$ "Credit" $\mid$ Potensial $=$ "Yes" $)=1163$ $/ 190 \overline{2}=0.61$

$\mathrm{P}($ Jns Bayar $=$ "Credit" $\mid$ Potensial $=$ "No" $)=1351 /$ $1359=0.99$

$\mathrm{P}($ Tenor $=$ " $<=25 " \mid$ Potensial $=$ "Yes") $=1897 /$ $1902=0.99$

$\mathrm{P}($ Tenor $="<=25 " \mid$ Potensial $=$ "No" $)=30 / 1359=$ 0.02

$\mathrm{P}(\mathrm{Usia}=$ "21-50" $\mid$ Potensial $=$ "Yes" $)=1552 / 1902$ $=0.81$

$\mathrm{P}($ Usia $=$ "21-50" $\mid$ Potensial $=$ "No" $)=1332 / 1359$ $=0.98$

- $\mathrm{X}=($ Pekerja $=$ No, Jenis Bayar $=$ Credit, Tenor $=$ " $<=25 "$, Usia $=$ 21-50 )

$\mathbf{P}(\mathbf{X} \mid \mathbf{C i}): \mathrm{P}(\mathrm{X} \mid$ Potensial $=$ "Yes" $)=0.48$ x $0.61 \mathrm{x}$ $0.99 \times 0.81=0.23$

$\mathrm{P}(\mathrm{X} \mid$ Potensial $=$ "No" $)=0.47 \times 0.99 \times 0.02 \times 0.98$ $=0.009$

$\mathbf{P}(\mathbf{X} \mid \mathbf{C i}) * \mathbf{P}(\mathbf{C i}): \mathrm{P}(\mathrm{X} \mid$ Potensial $=$ "Yes" $) * \mathrm{P}$ $($ Potensial $=$ "Yes" $)=0.13$

$\mathrm{P}(\mathrm{X} \mid$ Potensial $=$ "No" $) * \mathrm{P}($ Potensial $=$ "No" $)$ $=0.003$

Jadi, X dimiliki oleh kelas ("Potensial = Yes")

Berikut adalah contoh perhitungan kelas Pelanggan Tidak Potensial:

- $\quad$ PCi: $\mathrm{P}($ Potensial $)=(\mathrm{Jml}$ Potensial $/ \mathrm{Jml}$ Data $)=$ Total P $($ Tidak Potensial $)=(\mathrm{Jml}$ Tidak Potensial $/$ Jml Data $)=$ Total $\mathrm{P}($ Potensial $)=1902 / 3261=$ $0.58 \mathrm{P}($ Tidak Potensial $)=1359 / 3261=0.41$

- Compute $P(X \mid C i)$ for each class

$\mathrm{P}($ Pekerja $=$ "No" $\mid$ Potensial $=$ "Yes" $)=931 /$ $1902=0.48 \mathrm{P}($ Pekerja $=$ "No" $\mid$ Potensial $=$ "No" $)$ $=639 / 1359=0.47$

$\mathrm{P}($ Jns_Bayar $=$ "Cash" | Potensial = "Yes" $)=350 /$ $1902=0.8$

$\mathrm{P}($ Jns_Bayar $=$ "Cash" $\mid$ Potensial $=$ "No" $)=4 /$ $1359=0.0029$

$\mathrm{P}($ Tenor $=$ " $<=25 " \mid$ Potensial $=$ "Yes" $)=1897 /$ $1902=0.99$

$\mathrm{P}($ Tenor $="<=25 " \mid$ Potensial $=$ "No") $=30 / 1359$ $=0.022$

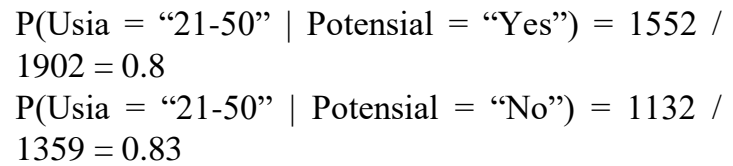

- $\quad X=($ Pekerja $=$ No, Jenis Bayar $=$ Cash, Tenor $=$ " $<=25$ ", Usia $=21-50$ )

$\mathbf{P}(\mathbf{X} \mid \mathbf{C i}): \mathrm{P}(\mathrm{X} \mid$ Potensial $=$ "Yes" $)=0.48 \times 0.8 \mathrm{x}$ $0.99 \times 0.8=0.07$

$\mathrm{P}(\mathrm{X} \mid$ Potensial $=$ "No" $)=0.47 \times 0.0029 \times 0.022 \mathrm{x}$ $0.83=0.000024$

$\mathbf{P}(\mathbf{X} \mid \mathbf{C i}) * \mathbf{P}(\mathbf{C i}): \mathrm{P}(\mathrm{X} \mid$ Potensial $=$ "Yes")* $\mathrm{P}$ $($ Potensial $=$ "Yes" $)=0.00023$

$\mathrm{P}(\mathrm{X} \mid$ Potensial $=$ "No")* $\mathrm{P}($ Potensial $=$ "No" $)=$ 0.009

Jadi, X dimiliki oleh kelas ("Potensial = No")

\section{Kalkulasi Akurasi Klasifikasi}

Metode yang digunakan untuk menguji tingkat akurasi model klasifikasi ini adalah metode holdout. Dalam metode ini, data asli dipartisi menjadi dua himpunan yang saling terpisah yang dinamakan training set dan test set. Model klasifikasi kemudian dibangun berdasarkan training set dan hasilnya kemudian dievaluasi dengan menggunakan testing set. Akurasi dari masing-masing metode klasifikasi dapat diestimasi berdasarkan akurasi yang diperoleh dari test set.

Sumber data tersebut akan dibagi dengan ketentuan $75 \%$ dari sumber data menjadi training data, dan $25 \%$ dari sumber data akan menjadi testing data (Jiawei, Han, 2011, p370) Training data: 4348 x 75\% = 3261 data. Testing data: $4348 \times 25 \%=1087$ data. Selanjutnya tabel confusion matrix digunakan untuk menghitung akurasi dari hasil klasifikasi.

Tabel 2. Tabel Confusion matrix

\begin{tabular}{|c|c|c|c|c|}
\cline { 3 - 4 } \multicolumn{1}{c|}{} & \multicolumn{2}{c|}{ Predicted Condition } & \multicolumn{1}{c}{} \\
\cline { 2 - 4 } & $\begin{array}{c}\text { Total Data } \\
=1087\end{array}$ & Potensial & $\begin{array}{c}\text { Tidak } \\
\text { Potensial }\end{array}$ & \\
\hline \multirow{4}{*}{$\begin{array}{c}\text { True } \\
\text { Condition }\end{array}$} & Potensial & $\mathrm{TP}=584$ & $\mathrm{FN}=17$ & $\mathrm{P}=601$ \\
\cline { 2 - 5 } & Tidak & $\mathrm{FP}=1$ & $\mathrm{TN}=485$ & $\begin{array}{c}\mathrm{N}= \\
486\end{array}$ \\
\hline & Potensial & $\mathrm{P}=585$ & $\mathrm{~N}=502$ & $\begin{array}{c}\mathrm{P}+\mathrm{N}= \\
186+ \\
988\end{array}$ \\
\hline
\end{tabular}

- $\quad T P$ adalah jumlah true positive yaitu jumlah data yang berhasil di prediksi oleh classifier dengan benar (misalkan jumlah data kelas "potensial" dari sampel yang secara benar dapat di prediksi sebagaimana mestinya oleh model klasifikasi),

- $P$ adalah jumlah sampel "potensial"

- $\quad T N$ adalah jumlah true negatives yaitu adalah kebalikan dari true positive (misalkan jumlah data kelas "Tidak Potensial" dari sampel yang benar 
dapat diprediksi sebagaimana mestinya oleh model klasifikasi).

- $\quad N$ adalah jumlah total sampel "Tidak Potensial"

- FP adalah false positives yaitu jumlah data yang salah di prediksi oleh classifier ("Tidak Potensial" diprediksi sebagai "Potensial").

- $\quad F N$ adalah False Negative yaitu jumlah data yang salah di prediksi oleh classifier ("Tidak Potensial" dipredksi sebagai "Tidak Potensial")

$$
\begin{aligned}
& \text { Sensivity }=\frac{T P}{T P+F N}=\frac{584}{584+17}=0.97=97 \% \\
& \text { Specificity }=\frac{T N}{T N+F P}=\frac{485}{485+1}=0,998=99.8 \% \\
& \text { Precision }=\frac{T P}{T P+F P}=\frac{584}{584+1}=0,998=99.8 \% \\
& \text { Recall }=\frac{T P}{T P+F N}=\frac{584}{584+17}=0.97=97 \% \\
& \text { Accuracy }=\text { Sensivity } \frac{P}{P+N}+\text { Specificity } \frac{N}{P+N} \\
& =0.97 \cdot \frac{1186}{1186+988}+0.998 \cdot \frac{988}{1186+988} \\
& =0.97 \times 0.54+0.998 \times 0.45 \\
& =0.52+0.45 \\
& =0.97 \text { atau } 97 \%
\end{aligned}
$$$$
\text { Error rate }=1-\text { Accuracy }=1-0.97=0.03
$$
atau $3 \%$

\section{Penjelasan:}

- $\quad$ Sensivity adalah ukuran tingkatan derajat classifier dapat mengenal positives samples ("potensial") berdasarkan jumlah true positives yang dapat diprediksi secara benar jika yang diberikan adalah sampel positives.

- Specificity adalah ukuran tingkatan derajat classifier dapat mengenal negatives samples ("tidak potensial") berdasarkan true negatives yang dapat diprediksi secara benar jika yang diberikan adalah sampel negatives.

- Recall adalah tingkat keberhasilan system dalam menemukan kembali sebuah informasi

- $\quad$ Precision adah ukuran tingkat ketepatan informasi yang diminta oleh pengguna dengan jawaban yang diberikan oleh system.

- Accuracy adalah derajat ukuran yang merupakan fungsi dari sensivity dan specificity model klasifikasi dalam melakukan prediksi.

- Error rate adalah untuk mengetahui ukuran tingkat kesalahan klasifikasi

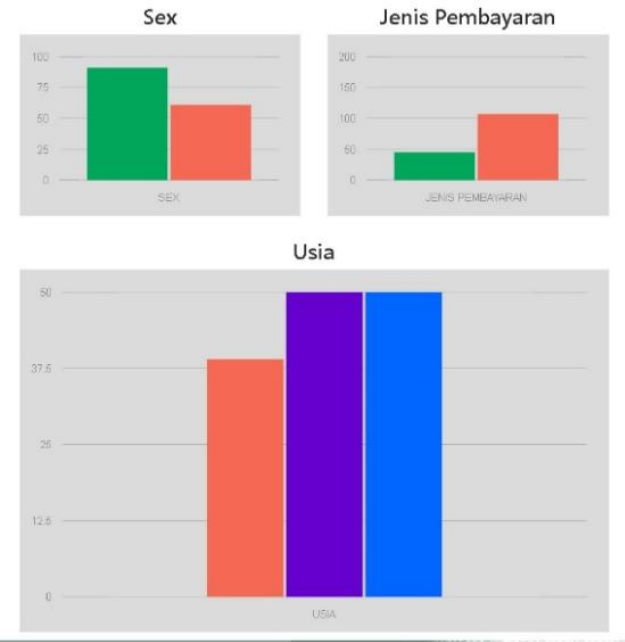

\section{Gambar 4. Grafik Pelanggan Berpotensial}

Gambar 4 dan 5 menampilkan hasil klasifikasi dengan metode niave bayes classification dalam bentuk tampilan visual. Gambar 4 menunjukan dilihat dari jenis kelamin atau sex, jumlah pelanggan potensial dengan sex atau jenis kelamin laki-laki lebih unggul dari pada sex atau jenis kelamin perempuan. Dilihat dari jenis pembayaran, jumlah pelanggan yang melakukan pembayaran secara credit lebih unggul yaitu 107 pelanggan. Sedangakan jumlah pelanggan yang melakukan pembayaran secara cash yaitu 45 pelanggan. Dilihat dari usia, jumlah pelanggan berpotensial dengan range 31-40 dan 41-50 memiliki nilai yang sama yaitu 50 pelanggan yang dimana berarti lebih unggul daripada range " $<21$ ", 21-30, dan $>51$

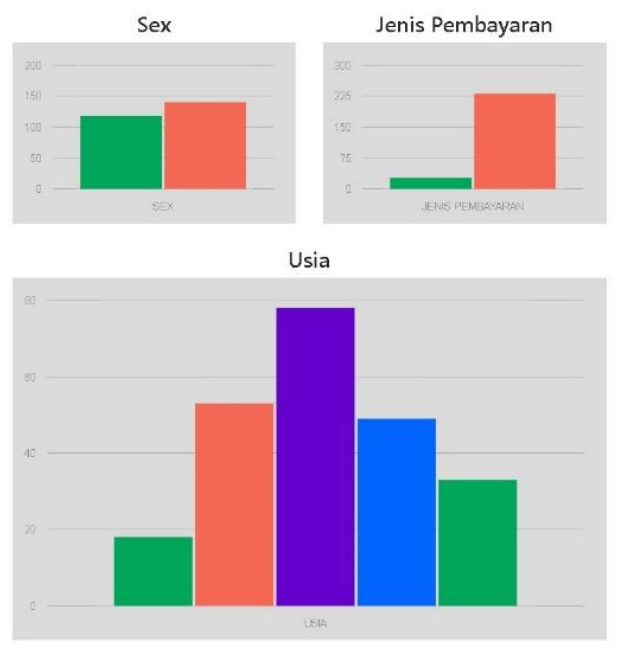

Gambar 5. Grafik Pelanggan Tidak Potensial

Gambar 5 menunjukan dilihat dari usia, jumlah pelanggan tidak potensial dengan range usia 31-40 lebih unggul dari pada range pelanggan tidak potensial dengan range <21. Dilihat dari jenis pembayaran, jumlah pelanggan tidak potensial dengan jenis pembayaran credit lebih unggul dari pelanggan tidak potensial dengan jenis pembayaran cash. Dilihat dari 
jenis kelamin atau sex, jumlah pelanggan tidak potensial berjenis kelamin perempuan lebih unggul dari pada jumlah pelanggan tidak potensial berjenis kelamin lakilaki.

\section{KESIMPULAN}

1. Data mining telah dapat memanfaatkan data riwayat transaksi pelanggan untuk melakukan suatu penelitian yang menghasilkan analisis mengenai klasifikasi pelanggan yang potensial dan tidak potensial. Atribut yang digunakan untuk menganalisa pelanggan (predictor attribute) tabel transaksi untuk klasifikasi pelanggan, terdiri atas: Pekerjaan, Jenis_Bayar, Tenor, dan Usia. Predictor attribute tersebut dipilih mewakili profil pelanggan secara umum.

2. Penelitian ini telah dapat mengklasifikasikan pelanggan menjadi kelas pelanggan potensial dan tidak potensial menggunakan metode naïve bayes dengan nilai sensitivity 97\%, specificity $99,8 \%$, precision $99,8 \%$, recall $97 \%$, accuracy $97 \%$, error rate $3 \%$.

3. Untuk penelitian lanjutan dapat dilakukan dengan menganalisis tabel pembelian untuk mengetahui jenis produk apa saja yang unggul yang sering dibeli atau dicari pelanggan.

\section{Acknowledgement}

Penulis mengucapkan terima kasih kepada Dila Ellin Ashari, Michael Surya Wijaya dan Risca Nuari mahasiswa School of Information Systems Program Studi Sistem Informasi yang telah membantu dalam pengumpulan dan pengolahan data.

\section{DAFTAR PUSTAKA}

Abdul Basith, Srikandi Kumadji, Kadarisman Hidayat (2014). Pengaruh Kualitas Produk Dan Kualitas Pelayanan Terhadap Kepuasan Pelanggan Dan Loyalitas Pelanggan. Jurnal Administrasi Bisnis, vol. 11 no. 1 Juni 2014, 1-8.

Dewa Ayu Wina Ariyunita Supar I Gusti Agung Ketut Gede Suasana (2017). Peran Kepuasan Pelanggan Dalam Memediasi Pengaruh Customer Relationship Management Terhadap Loyalitas Pelanggan. E-Jurnal Manajemen Unud, Vol. 6, No. 3, 2017, 1534-1563.

Fathur Rahman dan Muhammad Iqbal Firdaus (2016). Penerapan Data Mining Metode Naïve Bayes Untuk Prediksi Hasil Belajar Siswa Sekolah Menengah Pertama (Smp). Al Ulum Sains dan Teknologi Vol.1 No, 2 Mei 2016, 76-78.
Jiawei Han, Micheline Kamber, and Jian Pei. (2012). Data mining : concepts and techniques (3rd ed). USA: Morgan Kaufmann Publishers is an imprint of Elsevier.

Mujib Ridwan, Hadi Suyono, dan M. Sarosa (2013). Penerapan Data Mining Untuk Evaluasi Kinerja Akademik Mahasiswa Menggunakan Algoritma Naive Bayes Classifier. Jurnal EECCIS Vol.7 No. 1, Juni 2013, 59-64.

Thomas M. Connolly z Carolyn E. Begg. (2015). Database Systems A Practical Approach to Design, Implementation, and Management (6th ed). United States: Publisher Services Authorized adaptation from the United States edition, entitled Database Systems: A Practical Approach to Design, Implementation, and Management, 6th edition, ISBN 978-0-13-294326-0, by Thomas Connolly and Carolyn Begg, published by Pearson Education (C) 2015.

Yisti Vita Via, Budi Nugroho, Alfian Syafrizal (2015). Sistem Pendukung Keputusan Klasifikasi Tingkat Keganasan Kanker Payudara Dengan Metode Naïve Bayes Classifier. SCAN vol. X No 2 Juni 2015, 1-6. 